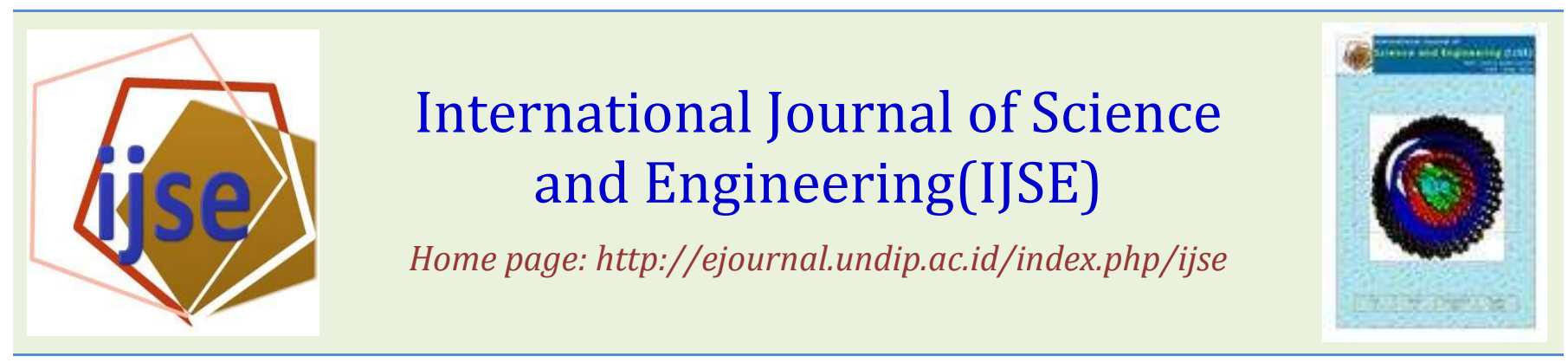

\title{
Investigation on the Effect of Shapes on the Drying Kinetics and Sensory Evaluation Study of Dried Jackfruit
}

\author{
PL Gan and PE Poh ${ }^{1}$ \\ ${ }^{1}$ Chemical Engineering Discipline, School of Engineering, Monash University, Malaysia Campus \\ Email: poh.phaik.eong@monash.edu
}

\begin{abstract}
Jackfruits are seasonal and highly nutritional fruits indigenous to the Southwestern rainforests of India. However much of the produce are spoilt annually due to poor preservation techniques. Minimal studies have been conducted on the drying kinetics of jackfruit and the effect of shapes on the drying kinetics. In this research, drying curves of three different shaped jackfruit slices were obtained using a convective oven at $40^{\circ} \mathrm{C}, 50^{\circ} \mathrm{C}, 60^{\circ} \mathrm{C}$ and $70^{\circ} \mathrm{C}$. Modified Midilli-Kucuk Model was found to be the best kinetic model for drying of jackfruits. At all temperatures, effective moisture diffusivity values and activation energy varied from $2.66 \times 10^{-10}-4.85 \times 10^{-10} \mathrm{~m}^{2} / \mathrm{s}$ and $16.08-20.07 \mathrm{~kJ} / \mathrm{mol}$ respectively. Drying was found to be most efficient at $50^{\circ} \mathrm{C}$ using the square shaped slices with a $R^{2}$, RMSE and SSE value of $0.9984,0.01127$ and 0.002668 respectively. Sensory evaluation of untreated and additive-added dried jackfruit slices was conducted by 40 untrained sensory panelists. Jackfruit with ascorbic acid and sugar coating had highest aesthetics value due to better retention of colour by ascorbic acid. However sugar coated jackfruit had the most favorable taste and smell. Further optimization must be done to satisfy consumers collectively to enable a highly marketable product.
\end{abstract}

Keywords-Activation energy; Effective diffusivity; Jackfruit; Oven drying kinetics; Sensory evaluation

Submission: Sept 12, $2014 \quad$ Corrected : October 1, 2014

Accepted: October 11, 2014

Doi: 10.12777 ijse.7.2.193-198

[How to cite this article: PL Gan \& PE Poh. (2014). Investigation on the Effect of Shapes on the Drying Kinetics and Sensory Evaluation Study of Dried Jackfruit,International Journal of Science and Engineering, Doi: 10.12777/ijse.7.2.193-198

\section{INTRODUCTION}

Jackfruit is one of the many seasonal local fruits available in Malaysia and is indigenous to the South-western rain forests of India (Boning, 2006). Jackfruits are fruits rich in energy, dietary fibre, potassium, magnesium, iron, vitamin Bcomplex, vitamin $\mathrm{C}$ and many other nutrients. They are also free from saturated fats and cholesterol making it an excellent choice of fruit for consumers (Umesh, et al., 2010; Swami, et al., 2012). Many methods of preservation have been applied to preserve the multi-nutritional jackfruit for the consumers. However, nearly $75 \%$ of jackfruit in India still gets spoilt annually due to lack of proper preservation, an integrated supply chain and storage facilities during peak seasons of harvesting (GlobalVillageFruit, 2013).

Preservation of food has been a way of life since prehistoric times to maintain the availability of food for human consumption. Among many methods of food preservation, drying or dehydration is one of the oldest techniques to prevent damage and spoilage of the food by microorganisms; subsequently, presenting higher stability of food for easier storage and transport (Mulet, 2011). Currently, most jackfruit studies compare final values of antioxidant activity, total phenolic contents and phytochemical aspects of the fruit after undergoing different drying techniques
(Shanmugapriya, Saravana, Payal, Mohammed, \& Binnie, 2011; Baliga, Shivashankara, Haniadka, Dsouza, \& Bhat, 2011). Minimal studies on the drying kinetics of the jackfruit have been studied because more researchers are concerned with the nutritional value of the jackfruit after drying. However, without a proper optimization of the drying process initially, conclusive values of nutritional values from different drying techniques should not be made.

In this experiment, the convection oven drying of jackfruit with three different shaped cuts was thoroughly studied for their drying kinetics to showcase the best fit of drying data in comparison to drying models from previous researches. The drying kinetics of jackfruit slices obtained can be used for better optimization of fruit dehydrators for jackfruits. Consecutively, the consumer acceptance of the dried jackfruit slices was analysed using sensory evaluation tests which target the three main senses namely sight, smell and taste. The preference typed sensory evaluation in this experiment allowed better understanding of the consumer demands and the perception of the general public on preserved dried jackfruit which was untreated compared to jackfruits which had food additives. The results of the sensory evaluation will provide a preliminary analysis for dried fruit manufacturers in Malaysia and especially India on whether to invest on the 
fabrication of a specific jackfruit oven dehydrator with drying technology using the proposed modelling obtained in this research.

\section{MATERIALS AND METHODS}

Materials used in this research were:

1) Fruits

A whole jackfruit (Artocarpus heterophyllus Lam.) with no apparent damage was purchased at the local market in Bukit Jelutong, Shah Alam, Selangor. The seeds of the jackfruit was plucked out from every bulb and disposed as the drying experiment does not cover the drying of the jackfruit seeds. Only fruits from the same jackfruit are tested as a sample.

2) Chemicals and Equipment

Food grade ascorbic acid (Euro-chemo Pharma Sdn. Bhd.) and white sugar (CSR Brand) are the two chemical additives used in jackfruit drying for sensory evaluation. Convection oven (Memmert, loading model 100-800) was used for convective drying of the jackfruit. Precision mass balance (A\&D Company Limited Model FX-3000i) was utilized as a mass balance for moisture loss calculations.

\section{Sample Preparation}

Each experiment at specified temperature utilizes the exact same batch of purchased fruit for every run to ensure consistency. Jackfruit bulbs were cut open and seeds were removed. Cuts of the jackfruit were made into three shapes, namely the triangle, rectangle and square. The weight of each sample was weighed to be approximately $10 \pm 0.5 \mathrm{~g}$ of pure jackfruit on the mass balance of $0.01 \mathrm{~g}$ accuracy. Sizes of all these samples must be fairly consistent and measured with sterilized measuring rulers (Tehranifar, Zarei, Nemati, Esfandiyar, \& Vasifeshenas, 2010). Dimensions of the jackfruit samples in three different shapes are shown below in Fig. 1 with an accuracy of $x \pm 5 \mathrm{~mm}$. Thicknesses of the slices varied on each slice but all were within the accuracy of $5 \mathrm{~mm} \pm 1 \mathrm{~mm}$.
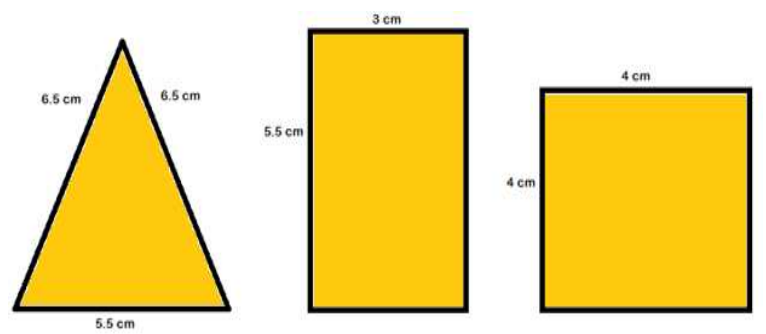

Figure 1. Shapes and Dimensions of Jackfruit Slices

\section{Sample Drying}

Total dry matter and determination of total moisture content was obtained by drying the jackfruit slices at $105^{\circ} \mathrm{C}$ to a uniform mass (AOAC, 1995) overnight. The total moisture content (\%water in $10 \pm 0.5 \mathrm{~g}$ of fruit) is expressed as shown in Equation 1 below.

Total Moisture Content $=$

$\frac{\text { Weight of water lost after drying at } 105^{\circ} \mathrm{C}(\mathrm{g})}{\text { Total weight of cut fruit }(10 \pm 0.5) \mathrm{g}} \times 100 \%$

The average total moisture content for the triangle, rectangle and square jackfruits were $71.9 \%, 71.4 \%$ and $73.1 \%$ wet basis respectively. These values were the main assumptions in calculation of final moisture contents achieved in jackfruit slices after total drying.

Convection oven drying of jackfruit was carried out at four temperatures; $40^{\circ} \mathrm{C}, 50^{\circ} \mathrm{C}, 60^{\circ} \mathrm{C}$ and $70^{\circ}$ because drying at these temperatures retains most of the fruit's natural quality in terms of solid gain and water loss ratio (Alves, et al., 2005). Before experimental runs, the oven was ensured to be operating for at least one hour to stabilize the air temperature in the drying chamber (Chowdhury, et al., 2010). Triplicate samples of all three shapes were removed at 30 minute intervals for weighing on electronic mass balance of $\pm 0.01 \mathrm{~g}$ accuracy. Drying process was completed when three consistent readings of weight were achieved. This weight was assumed to be the equilibrium weight of the dried jackfruit at the particular drying temperature. Typically, equilibrium moisture content of unprocessed dried fruit should range from below $10 \%$ to $25 \%$ (Joslyn, 2012) with a general acceptability of $20 \%$ for most dried fruits (Reynolds, et al., 1993). Repeatability tests were done twice under the exact same conditions of experimental procedures, instruments and location to ensure the accuracy of the experimental results.

\section{Mathematical Modelling}

Non-linear regression analysis was performed using MATLAB R2012b. All fitting calculations were done in MATLAB with the nine semi-theoretical and empirical thin layer drying models namely the Newton Model, the Page Model, the Modified Page Model, the Henderson and Pabis Model, the Logarithmic Model, the Midilli-Kucuk Model, the Modified Midilli-Kucuk Model, the Diffusion Approach Model and the Wang and Singh Model to identify the constant parameters in each separate model. In thin layer drying models, the non-dimensional moisture ratio $\left(M_{R}\right)$ is expressed as shown in Equation 2 below.

$M_{R}=\frac{M-M_{e}}{M_{o}-M_{e}}(2)$

The indicator to evaluate the best fit among the nine thin layer drying models to the experimental data was the model with the highest $\mathrm{R}^{2}$ and lowest RMSE and SSE values.

\section{Sensory Evaluation}

The sensory evaluation was a preference test using a set hedonic scale. The 40 untrained panellists were from an age group of 18-40. The evaluation space was conducted in a well-lighted area and timed from the mid-morning to early afternoon for the best judgment of taste (Rasco, 2006). Communication between all subjects was strictly prohibited to prevent side-tracked judgment. The sensory panellists were asked to sign a consent form as required by Monash University before given a set of instructions on paper to conduct the sensory test. Panellists were ensured to be free from taste perception disorders, odour perception disorders, colour blindness, denture defects, allergies, on medical treatment and prone to infections of the throat and nose. Panellists were not informed about the differences between samples used in the sensory testing but were assured of its safety. They were instructed to evaluate each quality parameter - appearance, smell, and taste individually to 
prevent the Halo Effect which occurs when they simultaneously evaluate different factors at one time (Lawless and Heymann, 2010). All the samples were presented in a random order on a white plate with different three digit number assigned to each sample to avoid the Order Effect from occurring. The Order Effect occurs when samples are perceived differently due to their position in their line-up. In smell evaluation, panellists sniffed prepared coffee beans between samples. During flavour evaluation, panellists rinsed their palates with room temperature water between samples. All the methodology for this evaluation conformed to standards of good practice in performing sensory evaluation studies (Lawless and Heymann, 2010). Evaluation sheets were collected after the test for variance analysis using the Nine Point Hedonic Acceptability Scale.

Table 1. The nine thin layer drying models used in this experiment

\begin{tabular}{|c|c|}
\hline Name of Model & Equation \\
\hline \multicolumn{2}{|c|}{$\begin{array}{l}\text { Semi Theoretical Models Derived From Newton's Law of } \\
\text { Cooling }\end{array}$} \\
\hline Lewis (Newton) & $M_{R}=\exp (-k t)$ \\
\hline Page & $M_{R}=\exp \left(-k t^{n}\right)$ \\
\hline Modified Page & $M_{R}=\exp \left(-(k t)^{n}\right)$ \\
\hline \multicolumn{2}{|c|}{$\begin{array}{c}\text { Semi Theoretical Models Derived From Fick's Second Law of } \\
\text { Diffusion }\end{array}$} \\
\hline $\begin{array}{l}\text { Henderson and } \\
\text { Pabis (Single } \\
\text { Term) }\end{array}$ & $M_{R}=a \exp (-k t)$ \\
\hline $\begin{array}{c}\text { Logarithmic } \\
\text { (Asymptotic) } \\
\text { Model }\end{array}$ & $M_{R}=a \exp (-k t)+c$ \\
\hline Midilli-Kucuk & $M_{R}=a \exp \left(-k t^{n}\right)+b t$ \\
\hline $\begin{array}{l}\text { Modified Midilli- } \\
\text { Kucuk }\end{array}$ & $M_{R}=a \exp \left(-k t^{n}\right)+b$ \\
\hline $\begin{array}{l}\text { Diffusion } \\
\text { Approach }\end{array}$ & $M_{R}=a \exp (-k t)+(-a) \exp (-k b t)$ \\
\hline \multicolumn{2}{|r|}{ Empirical Models } \\
\hline Wang and Singh & $M_{R}=1+a t+b t^{2}$ \\
\hline
\end{tabular}

\section{Drying Kinetics}

\section{RESULT AND DISCUSSION}

Drying at $40^{\circ} \mathrm{C}, 50^{\circ} \mathrm{C}, 60^{\circ} \mathrm{C}$ and $70^{\circ} \mathrm{C}$ took $14,12,10.5$ and 9 hours respectively. These values show a major reduction of 2 drying hours when drying temperature was changed from $40^{\circ} \mathrm{C}$ to $50^{\circ} \mathrm{C}$ as compared to only a 1.5 and 1 hour reduction when drying temperature were changed from $50^{\circ} \mathrm{C}$ to $60^{\circ} \mathrm{C}$ and $60^{\circ} \mathrm{C}$ to $70^{\circ} \mathrm{C}$ respectively. Typically, the jackfruit slices reached equilibrium moisture content of $16.7 \%, 5.8 \%, 20.3 \%$ and $5.1 \%$ at $40^{\circ} \mathrm{C}, 50^{\circ} \mathrm{C}, 60^{\circ} \mathrm{C}$ and $70^{\circ} \mathrm{C}$ respectively which were all reasonable moisture contents for dried fruits.

Generally, the highest $\mathrm{R}^{2}$ values will coexist with the lowest RMSE and SSE values. This will be the main criterion to determine conclusively on the most appropriate thin layer drying model. The Wang and Singh Model was found to have the lowest $R^{2}$ values in drying curves of every experiment, thus it is not a preferred drying model for jackfruit drying. Furthermore, with the exception of the Wang and Singh model, the $\mathrm{R}^{2}$ values for all three different shaped jackfruits at each temperature were fairly similar ranging for 0.99 to 0.999 .

From comparison of the remaining eight models for different shapes at a fixed temperature based on the highest $\mathrm{R}^{2}$ and lowest RMSE and SSE values, the Modified MidilliKucuk model was found to be the most appropriate thin layer drying model. The $\mathrm{R}^{2}$, RMSE and SSE values for each particular shape and temperature using the Modified Midilli-Kucuk model are tabulated as follows.

Table 2. $\mathrm{R}^{2}$, RMSE and SSE values for triangular, rectangular and square shaped jackfruit slices with the Modified Midilli-Kucuk model

\begin{tabular}{|c|c|c|c|c|}
\hline Shape & $\begin{array}{c}\text { Temp. } \\
\left({ }^{\mathbf{0}} \mathbf{C}\right)\end{array}$ & $\mathbf{R}^{\mathbf{2}}$ & $\mathbf{R M S E}$ & SSE \\
\hline \multirow{4}{*}{ Triangle } & 40 & 0.997 & 0.00461 & 0.0005322 \\
\cline { 2 - 5 } & 50 & 0.9968 & 0.01585 & 0.005277 \\
\cline { 2 - 5 } & 60 & 0.9985 & 0.01102 & 0.001821 \\
\cline { 2 - 5 } & 70 & 0.9986 & 0.01029 & 0.0018 \\
\hline \multirow{5}{*}{ Rectangle } & 40 & 0.9989 & 0.00924 & 0.002221 \\
\cline { 2 - 5 } & 50 & 0.999 & 0.00881 & 0.001632 \\
\cline { 2 - 5 } & 60 & 0.999 & 0.00904 & 0.001226 \\
\cline { 2 - 5 } & 70 & 0.9993 & 0.00711 & 0.0008598 \\
\hline \multirow{5}{*}{ Square } & 40 & 0.9994 & 0.00685 & 0.001173 \\
\cline { 2 - 5 } & 50 & 0.9984 & 0.01127 & 0.002668 \\
\cline { 2 - 5 } & 60 & 0.997 & 0.01584 & 0.003765 \\
\cline { 2 - 5 } & 70 & 0.9989 & 0.00924 & 0.001452 \\
\hline
\end{tabular}

Drying at temperatures above $50^{\circ} \mathrm{C}$ was found to be inappropriate for jackfruit slices because darkening of fruit was very apparent as compared to drying at lower temperatures. This phenomenon was also found in previous experiment by Chowdhury (2010). Drying time for $40^{\circ} \mathrm{C}$ was also too lengthy compared to drying at other temperatures. Thus, from all justifications mentioned, $50^{\circ} \mathrm{C}$ was found to be the optimum temperature for drying of the three differently shaped jackfruit slices.

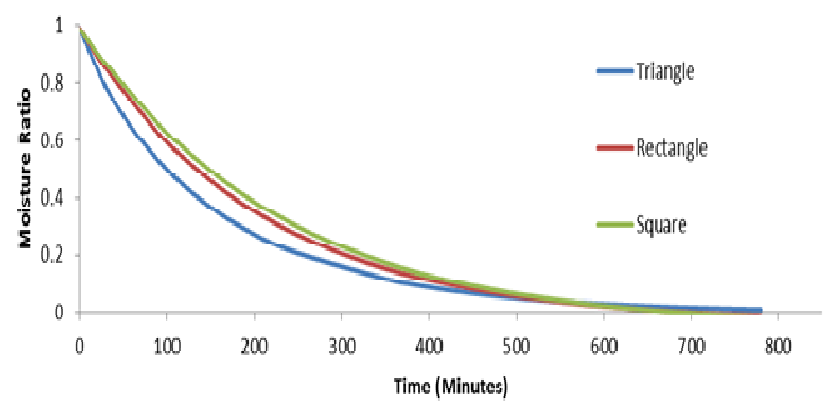

Figure 2. Drying curves for jackfruit slices at $50^{\circ} \mathrm{C}$ using the simulated values by the Modified Midilli-Kucuk model 
Effective Moisture Diffusivity and Activation Energy

A simple diffusion model based on Fick's $2^{\text {nd }}$ Law of Diffusion was used for calculation of effective moisture diffusivity of the three different shaped jackfruit slices. Assumptions of uniform initial moisture distribution, negligible external resistance and drying from the top of the sample was involved in these calculated values. From these assumptions, the equation is written in the following form:

$$
\ln \left(\frac{M-M_{e}}{M_{o}-M_{e}}\right)=\ln \left(\frac{8}{\pi^{2}}\right)-\frac{D_{e f f} \pi^{2}}{L^{2}} t
$$

Table 3. Effective moisture diffusivity values for different shaped jackfruit slices

\begin{tabular}{|c|c|c|c|}
\hline \multirow{2}{*}{$\begin{array}{c}\text { Temp } \\
\left({ }^{\circ} \mathbf{C}\right)\end{array}$} & \multicolumn{3}{|c|}{ Effective Moisture Diffusivity, $D_{\text {eff }}\left(\mathbf{m}^{2} / \mathbf{s}\right)$} \\
\cline { 2 - 4 } & \multicolumn{3}{|c|}{ Type of Jackfruit Slice } \\
\hline & Triangle & Rectangle & Square \\
\hline $\mathbf{4 0}$ & $2.755 \times 10^{-10}$ & $2.660 \times 10^{-10}$ & $2.883 \times 10^{-10}$ \\
\hline $\mathbf{5 0}$ & $2.970 \times 10^{-10}$ & $2.897 \times 10^{-10}$ & $3.081 \times 10^{-10}$ \\
\hline $\mathbf{6 0}$ & $4.094 \times 10^{-10}$ & $4.516 \times 10^{-10}$ & $4.125 \times 10^{-10}$ \\
\hline $\mathbf{7 0}$ & $4.658 \times 10^{-10}$ & $4.852 \times 10^{-10}$ & $4.776 \times 10^{-10}$ \\
\hline
\end{tabular}

Effective moisture diffusivity values generally increased with increase in drying temperature. This is due to the dependence of $D_{\text {eff }}$ on temperature as shown in the Equation 4 below. When the temperature rises, the value of $D_{\text {eff }}$ will increase(Goyal, et al., 2007). Effective moisture diffusivity values were found to be in the general range of $10^{-9}$ to $10^{-11} \mathrm{~m}^{2} / \mathrm{s}$ for drying of food materials and comparable to values of by past experiments of jackfruit drying by Chowdhury (2010) and Giraldo-Zuniga (2006). Thus, it can be concluded that the results of the calculated $D_{e f f}$ values are in good agreement with previous reported values. At drying temperatures of $40^{\circ} \mathrm{C}$ and $50^{\circ} \mathrm{C}$, square shaped slices were found to have the highest values of $D_{\text {eff }}$ followed by triangles and lastly rectangles. However, at drying temperatures of $60^{\circ} \mathrm{C}$ and $70^{\circ} \mathrm{C}$, rectangle shaped slices had the highest $D_{\text {eff }}$ values followed by squares and lastly triangles. Having low effective moisture diffusivity values is unfavourable to the drying process, thus it is safe to conclude that among the three shaped slices, square shaped slices are generally the most appropriate shape for drying of jackfruit slices for mass production.

The diffusivity of jackfruit slices is often expressed by an Arrhenius equation as shown in Equation 4 below. Linearization of the equation will be able to determine the activation energy of diffusion by plotting a graph of $\ln \left(D_{\text {eff }}\right)$ versus the reciprocal of absolute temperature, $T(K)$.

$$
\ln \left(D_{e f f}\right)=\ln \left(D_{e}\right)-\frac{E_{A}}{R(T+273.15)}
$$

Table 4. Maximum diffusion coefficient and activation energy for different shaped jackfruit slices

\begin{tabular}{|c|c|c|c|}
\hline Shape & Triangle & Rectangle & Square \\
\hline $\mathbf{D}_{\mathbf{0}}\left(\mathbf{m}^{\mathbf{2}} / \mathbf{s}\right)$ & $1.74 \times 10^{-7}$ & $5.70 \times 10^{-7}$ & $1.33 \times 10^{-7}$ \\
\hline $\begin{array}{c}\mathbf{E}_{\mathbf{A}} \\
(\mathbf{J} / \mathbf{m o l})\end{array}$ & 16900.807 & 20072.774 & 16079.338 \\
\hline
\end{tabular}

From calculations above, the activation energy of diffusion was lowest for square slices followed by triangles and rectangle. The values ranged from $16.08 \mathrm{~kJ} / \mathrm{mol}$ to $20.07 \mathrm{~kJ} / \mathrm{mol}$. Lower activation energies are preferable for drying processes as drying time and energy consumption can be lowered (Minaei, et al., 2011). Overall, due to the highest effective moisture diffusivity and lowest activation energy calculated in the experiment, square shaped jackfruit slices are justified to be the most appropriate model for drying of jackfruits.

Thus, by optimization of the Modified Midilli-Kucuk model, drying temperature of $50^{\circ} \mathrm{C}$ and most effective squared shape slices, the most appropriate thin layer equation proposed was defined as:

$$
M R=1.027 \exp \left(-0.003736 t^{1.03}\right)-0.0427
$$

\section{Sensory Evaluation}

Forty consumers evaluated jackfruit slices of three different attributes. The jackfruit slices dried for this sensory evaluation were square shaped and dried in convection oven at drying temperature of $50^{\circ} \mathrm{C}$. The three different attributes are namely a jackfruit slice with no additives (Code: C), a jackfruit slice coated with fine white sugar at the end of drying (Code: $\mathrm{S}$ ) and a jackfruit slice pre-treated with an ascorbic acid and sugar solution for 2-3 minutes prior to drying (Code: AA). Results were analysed and summarized in Table 4 from evaluation of appearance, smell and taste of jackfruit samples on the set hedonic scale. The set hedonic scale used for this preference test had scores ranging from 1 to 9 which placed 5 as an average score.

Table 5. Sensory evaluation calculated scores

\begin{tabular}{|c|c|c|c|}
\hline \multirow{2}{*}{$\begin{array}{c}\text { Type of } \\
\text { Jackfruit }\end{array}$} & $\begin{array}{c}\text { Mean } \\
\text { Score }\end{array}$ & Variance & $\begin{array}{c}\text { Standard } \\
\text { Deviation }\end{array}$ \\
\cline { 2 - 4 } & \multicolumn{3}{|c|}{ Aesthetic Value of Jackfruit } \\
\hline C & 4.750 & 2.5513 & 1.5973 \\
\hline S & 5.250 & 2.9615 & 1.7209 \\
\hline AA & 5.525 & 3.0250 & 1.7393 \\
\hline \multicolumn{3}{|c|}{ Smell of Jackfruit } \\
\hline C & 5.325 & 2.6865 & 1.6391 \\
\hline S & 5.550 & 2.4077 & 1.5517 \\
\hline AA & 5.175 & 4.0968 & 2.0241 \\
\hline & \multicolumn{3}{|c|}{ Taste of Jackfruit } \\
\hline C & 6.225 & 1.7173 & 1.3105 \\
\hline S & 6.425 & 2.6609 & 1.6312 \\
\hline AA & 3.850 & 4.6436 & 2.1549 \\
\hline
\end{tabular}


These values show that a combination of all methods can possibly be the most efficient way to innovate a final product of dried jackfruit which will be able to satisfy consumers in all three main sensory aspects.

A very interesting discovery in the analysis of scores was found in the analysis of AA samples. The spread of scores around the mean score was larger compared to $\mathrm{C}$ and $\mathrm{S}$ samples for all three sensory evaluations. This finding shows that pre-treatment of an ascorbic acid and sugar solution on jackfruit slices may result in higher or lower preferability in consumers. Dried jackfruit treated with ascorbic acid and sugar solution was estimated to be the most preferred type of dried jackfruit because of better colour retention by ascorbic acid (food colour retention agent) and additional sweet taste. This finding was supported by AA jackfruits achieving the highest score compared to $\mathrm{C}$ and $\mathrm{S}$ samples in the aesthetics sensory test. However, the sour taste of the ascorbic acid in the pretreatment solution may have offset the natural sweet taste of jackfruit to a high extent, resulting in the AA jackfruits having the lowest score in the taste test. Thus, optimization must be done on this pre-treatment method to ensure its capability of being an efficient pre-treatment method for jackfruit drying.

In the sensory test, a question was asked to determine the overall acceptability of the three different types of dried jackfruits. This question was to determine the best jackfruit for mass production. The pie chart below illustrates the percentage breakdown of the overall acceptability as rated by the Malaysian consumer market.

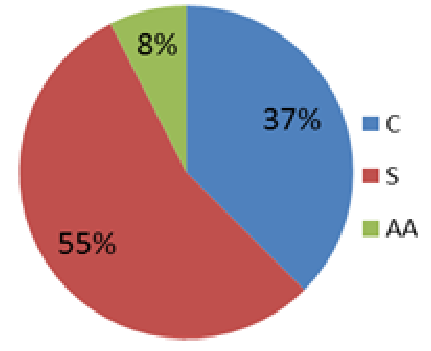

Figure 3.Overall percentage breakdown for most preferred jackfruit slice in all three sensory tests

From Fig. 3, more than half of the consumer sample chose jackfruit with sugar coating (S) as their most preferred dried jackfruit slice. This was also an expected outcome as Malaysian people are famous for having high preference of sweet foods (Loh, 2009). Only a small percentage $(8 \%)$ of consumers preferred the AA samples due to its sour taste as commented by many of the sensory evaluation panellists. This further shows that despite having the best aesthetic value, AA samples will not be preferred by consumers at the purchase counter. Besides that, it can be inferred that drastic change of the naturally sweet jackfruit into a sour tasting dried fruit was not preferred by consumers. Furthermore, this low percentage may also be due to the fact that jackfruits are known to be fruits of somewhat an acquired taste.

\section{IV.CONLUSIONS}

Based on the nine thin layer drying models, the modified Midilli-Kucuk model was best fitted to the experimental data of the jackfruit drying process. Drying temperature of $50^{\circ} \mathrm{C}$ was found to be the most optimum temperature for jackfruit drying. Amongst the three proposed shapes for drying of jackfruit slices, the square shaped slices were the most suitable drying shape configuration due its highest effective moisture diffusivity $\left(3.081 \times 10^{-10} \mathrm{~m}^{2} / \mathrm{s}\right)$ and lowest activation energy (16079.338 J/mol) values. Dried jackfruit slices with extra sugar coating was found to be the most preferred dried jackfruit in the sensory evaluation test. This was an unfortunate discovery because extra sugar will be detrimental to our initial objective of making dried jackfruit into a nutritional snack as an alternative to unhealthy junk food. Thus, further work should be done to optimize drying kinetics of jackfruit to ensure the procurement of dried jackfruit chips at a more satisfactory level without the addition of sugar. These findings may be applicable to design of fan-controlled oven dehydrators for jackfruits in India to prevent spoilage and wastage of the fruit due to overproduce during seasonal months.

\section{ACKNOWLEDGMENT}

The authors would like to acknowledge Monash University Malaysia Campus for the financial support provided for this project.

\section{REFERENCES}

Alves, D. et al. (2005). Osmotic Dehydration of Acerola Fruit (Malpighia Punicifolia L.). Journal of Food Engineering, 68: 99-103; doi: 10.1016/j.jfoodeng.2004.05.042

AOAC, (1995). Official Methods of Analysis. Washington DC: Association of Official Analytical Chemistry. ISBN: 0935584544

Baliga, M. et al. (2011). Phytochemistry, nutritional and pharmacological properties of Artocarpus heterophyllus Lam (Jackfruit): A Review. Food Research International, 44: 1800-1811; doi: 10.1016/j.foodres.2011.02.035

Boning, C., (2006). Florida's Best Fruiting Plants: Native and Exotic Trees, Shrubs, and Vines. 1st ed. Florida: Pineapple Press Inc. ISBN: 1561643726

Chowdhury, M., et al. (2010). Mathematical Modeling of Thin-Layer Drying of Jackfruit Leather. Journal of Food Processing and Preservation, 35: 797-805; doi: 10.1111/j.17454549.2011.00531.x

Giraldo-Zuniga, A. et al. (2006). Kinetic Drying Experimental Data and Mathematical Model For Jackfruit (Artocarpus integrifolia) Slices. Ciencay Technologia Alimentaria, 5(2): 89-92; doi: $10.1080 / 11358120609487676$

GlobalVillageFruit. (2013). Introducing Jackfruit, the Wonderfuit (TM) of the World, USA: GlobalVillageFruit; http://www.globalvillagefruit.com (Accessed $17^{\text {th }}$ May 2014)

Goyal, R., et al. (2007) Mathematical modelling of thin layer drying kinetics of plum in a tunnel dryer.Journal of Food Engineering, 79: 176180; doi: 10.1016/j.jfoodeng.2006.01.041

Joslyn, M.A. (2012). Methods in Food Analysis: Applied to Plant Products. New York: Academic Press Inc. ISBN: 0123901561

Lawless, H. \& Heymann, H. (2010). Principles of Good Practice. In: D. Heldman, ed. Sensory Evaluation of Food. New York: Springer, pp. 57-77. ISBN: 1441964878

Loh, J. (2009). Bitter truth about our sweet tooth, Malaysia: Persatuan Diabetes Malaysia; http://www.diabetes.org.my/article.php?aid=642 (Accessed $17^{\text {th }}$ May 2014)

Minaei, S., et al. (2011). Influence of drying methods on activation energy, effective moisture diffusivity and drying rate of pomegranate arils (Punica Granatum). Australian Journal of Crop Science, 6(4): 584-591; ISSN: 1835-2693 
Mulet, A. (2011). Drying of Fruits and Vegetables-Overview on Some Basic Principles and Applications, Valencia: Universidad Politecnica De Valencia; http://www.uco.es/grupos/redtematica/download/expert3.pdf (Accessed $17^{\text {th }}$ May 2014)

Rasco, B. (2006). Experimental Design and Sensory Analysis, Washington: Washington State University; $\underline{\text { http://public.wsu.edu/ rasco/fshn4202005/EDSA.pdf }}$ (Accessed $17^{\text {th }}$ May 2014)

Reynolds, Susan \& Williams, P. (1993). So Easy To Preserve, Georgia: The University of Georgia; ASIN: B00071O1T8

Shanmugapriya, K. et al. (2011). Antioxidant Activity, Total Phenolic and Flavenoid Contents of Artocarpus Heterophyllus and Manilkara Zapota Seeds and Its Reduction Potential. International Journal of
Pharmacy and Pharmaceutical Science, 3(5): 1-5; ISSN: 09751491

Swami, S., et al. (2012). Jackfruit and Its Many Functional Components as Related to Human Health: A Review. Comprehensive Reviews in Food Science and Safety, 11: 565-576; doi: 10.1111/j.15414337.2012.00210.x

Tehranifar, A. et al. (2010). Investigation of Physio-chemical Properties and Antoxidant Activity of Twenty Iranian Pomegranate (Punica Granatum L.) Cultivars. Science Horticultures, 126: 180-185; doi: 10.1016/j-scientia.2010.07.001

Umesh, J., et al. (2010). Evaluation of Antioxidant Capacity and Phenol Content in Jackfruit (Artocarpus heterophyllus Lam.) fruit pulp. Plant Foods Hum Nutrition, 65: 99-104; doi: 10.1007/s11130010-0155-7 